\section{Identifying Host Resistance to Phytophthora cinnamomi in Hybrid Progeny of Castanea dentata and Castanea mollissima}

\author{
M. Taylor Perkins and Anna Claire Robinson \\ Department of Biology, Geology, and Environmental Science, The University \\ of Tennessee at Chattanooga, Chattanooga, TN 37403
}

Martin L. Cipollini

Department of Biology, Berry College, Mount Berry, GA 30149

\section{J. Hill Craddock ${ }^{1}$}

Department of Biology, Geology, and Environmental Science, The University of Tennessee at Chattanooga, Chattanooga, TN 37403

Additional index words. american chestnut, chinese chestnut, ink disease, phytophthora root rot, germplasm conservation, disease resistance breeding, tree breeding

\begin{abstract}
Phytophthora cinnamomi Rands, the causal pathogen of phytophthora root rot (PRR) of chestnut, is one of the main obstacles to growth of american chestnut [Castanea dentata (Marsh.) Bork.] in the southern part of its distribution. To facilitate introgression of PRR resistance of chinese chestnut $(C$. mollissima Blume) into a $C$. dentata genetic background, we assessed the disease resistance of 10 interspecific hybrid families derived from potentially resistant $\boldsymbol{C}$. mollissima cultivars. Hybrid progeny were inoculated with $P$. cinnamomi in the nursery and assessed for root lesion severity after 1 year of growth. Asymptomatic plants were transplanted to a $P$. cinnamomi-positive orchard and evaluated for survival midway through the following growing season. During the nursery experiment, 8 of 10 hybrid families were not significantly different from susceptible $C$. dentata controls for average disease resistance scores. However, multiple asymptomatic individuals were identified in each of the eight families. Two of the $\mathbf{1 0}$ hybrid families were not significantly different from the resistant $C$. mollissima and $C$. henryi controls. In the $P$. cinnamomi-positive orchard, the prescreened hybrid families displayed a greater proportion of survivors than backcross families that had not been prescreened for $P$. cinnamomi resistance. Hybrid plants that have survived 2 years of growth in $P$. cinnamomi-infested potting media and soils represent an important step toward the production of genetically diverse chestnut populations in the southeastern United States that combine the PRR resistance of $C$. mollissima with the morphology and local adaptation of $C$. dentata.
\end{abstract}

PRR is a catastrophic disease of the three North American Castanea taxa: american chestnut [C. dentata (Marsh.) Borkh.], allegheny chinquapin [C. pumila (L.) Mill. var. pumila], and ozark chinquapin [C. pumila (L.) Mill. var. ozarkensis (Ashe) Tucker] (Crandall et al., 1945; Jeffers et al., 2009, 2012; Sena et al., 2018). The principal causal pathogen, the oomycete Phytophthora cinnamomi Rands, is suspected to have been introduced to one of the coastal ports of the southeastern United States via ornamental plants from eastern Asia in the early 19th century (Anagnostakis, 2001; Crandall et al., 1945). Analyses of historical records have implicated $P$. cinnamomi in the widespread dieback of $C$. dentata and $C$. pumila var. pumila in the southeastern Coastal Plain and Piedmont during the 19th century (Anagnostakis, 2001; Crandall et al., 1945). Phytophthora cinnamomi has been isolated from dying chestnuts and chinquapins across the southeastern United States, as far north as Pennsylvania and as far west as Arkansas (Crandall et al., 1945; Fitzsimmons, 2016; Jeffers et al., 2009). Symptoms of PRR include necrosis of roots, leaf chlorosis, wilting of foliage, and branch dieback (Crandall et al., 1945; Jeffers et al., 2009). Unless symptoms are controlled with potassium phosphites or similar chemicals (James, 2011a), PRR will cause the death of susceptible plants 3 weeks to several years after the initial infection (Crandall et al., 1945; Jeffers et al., 2009). Phytophthora cinnamomi is one of the most serious obstacles to growth of $C$. dentata throughout its former range because of the prevalence of the pathogen in a variety of soils across the southeast and the fact that PRR is ultimately fatal to North American Castanea species.

In addition to PRR, the North American Castanea species are severely affected by chestnut blight, caused by the ascomycete Cryphonectria parasitica (Murr.) Barr (Alexander et al., 2005; Anagnostakis, 2001; Paillet, 1993, 2002). Since 1989, The American Chestnut Foundation (TACF) and collaborators have used the backcross method to introgress blight resistance from chinese chestnut (C. mollissima Blume) into a $C$. dentata genetic background (Hebard, 2005; Westbrook, 2017). In a recent review of TACF's backcross breeding program, Steiner et al. (2017) reported that progeny tests have validated experimentally expectations that a blight-resistant population of $C$. dentata-type trees can be constructed using introgression of extraspecific alleles for blight resistance. However, because $P$. cinnamomi was only recently recognized as an impediment to $C$. dentata restoration, TACF's breeding program has not selected for PRR resistance. As a result, PRR has caused the failure of entire experimental orchards and forest progeny tests before advanced backcross trees could be assessed for chestnut blight resistance (Clark et al., 2014; Jeffers et al., 2009, 2012; Sisco, 2009).

In response to PRR-induced mortality of potentially blight-resistant hybrid seedlings, a screening program was initiated in 2004 to detect PRR-resistant seedlings in TACF's backcross lines (James, 2011a, 2011b; Jeffers et al., 2009, 2012). Results of this screening program have indicated that PRR-resistant seedlings are present at low frequency in some, but not all, TACF advanced backcross lines $\left(\mathrm{BC}_{2} \mathrm{~F}_{\mathrm{x}}, \mathrm{BC}_{3}\right.$ $\mathrm{F}_{\mathrm{x}}$, and $\mathrm{BC}_{4} \mathrm{~F}_{\mathrm{x}}$ generations) that have been selected for blight resistance - most notably in lines derived from the blight-resistant hybrid cultivars Clapper and Graves (Jeffers et al., 2009). More recent resistance screening efforts showed that PRR resistance was also present in descendants of TACF's third major source of blight resistance, C. mollissima 'Nanking' (Zhebentyayeva et al., 2014).

Studies of the quantitative trait loci (QTL) associated with resistance to $P$. cinnamomi have aided breeding efforts by demonstrating that this trait is controlled by a limited number of genomic regions and may therefore be a practicable target for markerassisted selection (Santos et al., 2017; Zhebentyayeva et al., 2014). Santos et al. (2017) identified QTLs for PRR resistance on linkage groups $\mathrm{E}$ and $\mathrm{K}$ of japanese chestnut (C. crenata Sieb. \& Zucc.), and QTLs for PRR resistance were found on the same two linkage groups of $C$. mollissima (T.N. Zhebentyayeva, The Pennsylvania State University, personal communication). These findings suggest common resistance mechanisms to $P$. cinnamomi infection across different species within the genus Castanea (Santos et al., 2017). However, candidate genes within these QTLs have not been tested for their effects, and there exists the possibility that the East Asian Castanea species may have multiple alleles that encode PRR resistance. Until the genetic control of PRR resistance is better understood, additional sources of resistance are desirable for chestnut breeding programs in the eastern United States, because different $C$. mollissima and $C$. crenata cultivars may have different alleles encoding resistance. Efforts to identify multiple sources of PRR resistance are also important because they will facilitate the 
introgression of different nut characteristics and other agronomically important traits into populations being tested for the commercial chestnut market.

Because of the high susceptibility of $C$. dentata to both PRR and chestnut blight, the growth of $C$. dentata-type trees across large portions of the southeastern United States requires planting trees that have host resistance to both pathogens. The objective of this study was to evaluate PRR resistance in 10 hybrid families derived from crosses between susceptible $C$. dentata trees and potentially resistant $C$. mollissima cultivars in a containment system, followed by outplanting the least symptomatic plants into a $P$. cinnamomipositive orchard and assessing their survival midway through the second growing season.

\section{Materials and Methods}

Plant materials. We used three approaches to generate hybrid progeny for PRR resistance screening. With the first approach, we performed controlled pollinations between interspecific $\mathrm{F}_{1}$ hybrids $(C$. dentata $\times$ C. mollissima) selected previously for high levels of resistance to chestnut blight (J.H. Craddock, unpublished data) and naturally occurring $C$. dentata trees from either Tennessee or Alabama, yielding eight firstbackcross $\left(\mathrm{BC}_{1}\right)$ families (Fig. 1A; Table 1). With the second approach, an $\mathrm{F}_{1}$ hybrid $(C$. dentata $\times$ C. mollissima) selected previously for blight resistance (J.H. Craddock, unpublished data) was open pollinated by its $F_{1}$ sibling planted in an adjacent position in the breeding orchard, yielding a group of $F_{2}$ progeny (Table 1 ). The $F_{1}$ hybrids in this experimental orchard have nonoverlapping

Received for publication 11 Oct. 2018. Accepted for publication 1 Dec. 2018.

This work was supported by a grant from the American Chestnut Foundation and a University of Tennessee at Chattanooga Provost Student Research Award to M. Taylor Perkins. We acknowledge additional support from the Summerfield Johnston Endowment for the Restoration of the American Chestnut, and the Bettie J. Smith FLP. We thank those who shared their time and expertise for this project: Paul H. Sisco for guidance regarding the "better backcross" and aspects of experimental design; Tatyana N. Zhebentyayeva for guidance regarding experimental design; Paola Zannini for breeding database management and assisting with implementation of the experiments and data collection; David Morris, Jack Agricola, and members of the Alabama Chapter of the American Chestnut Foundation for providing pollen and for assisting in the greenhouse; Clint Neel for providing pollen and seeds; and Thomas M. Saielli of the American Chestnut Foundation for providing American chestnut seeds. Special thanks are given to Steven N. Jeffers and Suzette Sharpe for providing guidance and resources for Phytophthora isolation, species identification, and design of disease resistance screening experiments. We thank Lisa W. Alexander and Jared W. Westbrook for reviewing the manuscript.

${ }^{1}$ Corresponding author. E-mail: hill-craddock@ utc.edu. phenology with backcross trees in the same orchard (10-14 d difference in anthesis). With the third approach, a male-sterile $\mathrm{F}_{1}$ hybrid $(C$. dentata $\times C$. mollissima $)$ selected previously for chestnut blight resistance (J.H. Craddock, unpublished data) was open-pollinated by neighboring advanced backcross trees (either $\mathrm{BC}_{3} \mathrm{~F}_{1}$ or $\mathrm{BC}_{4} \mathrm{~F}_{1}$ generations) selected previously for chestnut blight resistance and several $C$. dentata morphological traits, yielding "better backcross" $\left(\mathrm{BB}_{1}\right)$ progeny that we refer to as a family in this study (Fig. 1B; Table 1). All $\mathrm{F}_{1}$ hybrids in this orchard were male-sterile; thus, only the selected $\mathrm{BC}_{3} \mathrm{~F}_{1}$ and $\mathrm{BC}_{4} \mathrm{~F}_{1}$ plants could contribute pollen. The third crossing strategy is justified because the $\mathrm{BB}_{1}$ progeny could inherit blight resistance from two sources: TACF's 'Clapper' line parent (i.e., paternal parent) and/or the C. mollissima cultivar used in our recent $F_{1}$ cross (i.e., maternal parent). The site conditions of the $F_{1}$ trees used for our $\mathrm{BC}_{1}, \mathrm{~F}_{2}$, and $\mathrm{BB}_{1}$ crosses were of particular importance, because nearly all the $F_{1}$ hybrids have exhibited several years of healthy growth in P. cinnamomi-positive orchards. The following $C$. mollissima cultivars were used as potential sources of resistance: 'Amy', 'Byron', 'Gideon', 'Lindstrom 99', 'Nanking', 'Payne', and 'Petersburg' (Table 1).

To perform controlled pollinations, we emasculated bisexual catkins and covered female flowers with corn pollinating bags about 1 week before anthesis. We collected staminate catkins from male parents, placed catkins on glass panes overnight to promote anther dehiscence, collected pollen in vials, and stored pollen at $3{ }^{\circ} \mathrm{C}$ until pollination was performed. We applied pollen to female flowers using a plastic vial lid or glass microscope slide and placed pollination bags over female flowers until nuts were harvested. To detect unintended outcrossing, for every 10 flowering shoots that were hand-pollinated, we treated one flowering shoot as a no-pollen control. Seeds were harvested in Sept. 2014 and Oct. 2014, and were stored in slightly moistened peatmoss at $3{ }^{\circ} \mathrm{C}$ until Spring 2015 .

PRR-resistant and -susceptible control plants were selected from species tested previously (Crandall et al., 1945; Jeffers et al., 2009). C. dentata seedlings provided by the American Chestnut Foundation were used as susceptible control plants, whereas seedlings of $C$. mollissima and C. henryi (Skan) Rehder and E.H. Wilson obtained from a cultivar trial in Chattanooga, $\mathrm{TN}$, were used as resistant control plants.

Nursery trials. In Mar. 2015, soil samples were collected from TACF breeding orchards in Greenback, TN (lat. $35.6281 \mathrm{~N}$, long. $-84.1040 \mathrm{~W}$ ) and McDonald, TN (lat. 35.0982 N, long. $-84.9531 \mathrm{~W}$ ), where plant death accompanied by PRR symptoms had been observed previously. Soils were baited for Phytophthora spp. using the bioassay of Ferguson and Jeffers (1999). P. cinnamomi isolates recovered from the two breeding orchards were accessioned in the Phytophthora culture collection of S.N. Jeffers (Clemson University). Using P. cinnamomi isolates from the TACF orchard in Greenback, TN, a V8- vermiculite inoculum was prepared following the protocol of Jeffers (2015).

In May 2015, seeds were planted outdoors in nursery containers at the University of Tennessee at Chattanooga. Nursery containers were filled with a soilless container mix consisting of pine bark, Canadian sphagnum peatmoss, and vermiculite (Sun Gro Metro-Mix 360; Agawam, MA). Seeds were planted $5 \mathrm{~cm}$ apart in five 229-L plastic nursery containers in a randomized complete block design.

Seedlings were inoculated with $P$. cinnamomi following the methods of Jeffers et al. (2009). Inoculations were performed in July, $\approx 12$ weeks after planting. To inoculate plants, a thin layer of inoculum was distributed evenly in 1- to 3-cm-deep furrows between rows of seedlings. The furrows were covered and the nursery containers were watered thoroughly. Nursery containers were watered daily throughout the growing season. The nursery containers were placed in small plastic swimming pools to retain effluent and prevent the spread of $P$. cinnamomi throughout the nursery. Chlorine tablets were added to the containment pools to kill P. cinnamomi in the irrigation effluent.

Seedlings were assessed for PRR symptom severity using the rating system developed by Jeffers et al. (2009). In January, we removed plants from their containers and gently washed the root systems to remove potting medium. We assigned symptom severity ratings to each of the plants using the root rot phenotyping system developed by Jeffers et al. (2009): 0 = healthy, no lesions observed on roots; $1=$ lesions observed on at least one lateral root; $2=$ lesions observed on the tap root; and $3=$ severe root rot, plant dead.

Orchard planting and survival. In Spring 2016, plants in the lowest symptom severity category (plants rated 0) were planted in TACF's Georgia Chapter's Lake Allatoona Orchard (Allatoona, GA; lat. $34.1871 \mathrm{~N}$, long. $-84.7065 \mathrm{~W})$, which was documented previously as $P$. cinnamomi positive. In Aug. 2016, survival was assessed of plants that had been prescreened for PRR resistance.

Data analysis. To evaluate the strength of PRR resistance in hybrid families compared with previous studies, we calculated a survival quotient (SQ) for each family, using the formula of Jeffers et al. (2009):

$$
\begin{aligned}
\mathrm{SQ}= & \frac{(1 \times \mathrm{n} 0)+(0.5 \times \mathrm{n} 1)+(0.25 \times \mathrm{n} 2)}{\text { Total number of seedlings }} \\
& \times 100,
\end{aligned}
$$

where $\mathrm{n} 0, \mathrm{n} 1$, and $\mathrm{n} 2$ are the number of seedlings rated 0,1 , and 2 , respectively. The SQ ranges from $0 \%$ to $100 \%$. High SQ values indicate resistance whereas low SQ values indicate susceptibility.

Using the raw symptom severity data, the effects of treatment (family) and block on symptom severity were assessed with a twoway analysis of variance, and differences among families were evaluated with Duncan's new multiple range test using the "easyanova" package (Arnhold, 2013) in $\mathrm{R}$ version 3.5.0 statistical software (R Core Team, 2018). 


\section{Results and Discussion}

In the nursery trial, PRR symptoms and seedling mortality were observed in every interspecific hybrid family and the susceptible $C$. dentata control group, whereas no plant mortality or PRR symptoms were observed in the resistant $C$. mollissima and $C$. henryi control groups, as expected (Fig. 2). Three of the $13 C$. dentata control plants exhibited no PRR symptoms at the end of the nursery trial, which indicates that some seedlings "escaped" infection during the first year of screening, probably because of uneven distribution of the pathogen across portions of the planting containers.

SQ values of hybrid families ranged from $56.5 \%$ to $89.6 \%$. The susceptible control species, $C$. dentata, had the lowest SQ value (48.1\%), whereas both resistant control species, C. mollissima and C. henryi, had the highest SQ values observed in the trial (100\%) (Fig. 2). A comparison of our SQ values with those of Jeffers et al. (2009) revealed that all but one of our hybrid families had greater SQ values than backcross families screened in an earlier study (Jeffers et al., 2009). Only one $\mathrm{BC}_{1}$ family in our study, TN-TTU-A4 $\times$ ALCLEB04, had an SQ value $(56.5 \%)$ similar to that of the most resistant cross reported by Jeffers et al. (2009): Hyko $\times$ JB575 (56.3\%). One explanation for this difference is that all hybrid families studied by Jeffers et al. (2009) resulted from a greater number of backcrosses to the susceptible species, $C$. dentata, than any of the families evaluated in our study. Furthermore, parent trees in the crosses of Jeffers et al. (2009) had not been selected for PRR resistance. Specifically, Jeffers et al. (2009) screened $\mathrm{BC}_{2} \mathrm{~F}_{\mathrm{x}}, \mathrm{BC}_{3}$ $\mathrm{F}_{\mathrm{x}}$, and $\mathrm{BC}_{4} \mathrm{~F}_{\mathrm{x}}$ progeny, whereas we screened eight $\mathrm{BC}_{1}$ families, one $\mathrm{F}_{2}$ family, and one $\mathrm{BB}_{1}$ family. Because PRR resistance in chestnut is thought to be under the control of multiple genes (Santos et al., 2017), it would be expected that Asian American $\mathrm{BC}_{1}$ hybrids would retain more alleles for resistance than later generation backcrosses to $C$. dentata if the parent trees were not selected for PRR resistance at every generation. A second possible explanation is that the strength of selection in the study of Jeffers et al. (2009) was greater. For example, the environment in the planting containers of Jeffers et al. (2009) may have been more favorable for the proliferation of $P$. cinnamomi, or our inoculum may not have been entirely successful. The latter scenario would have resulted in an

uneven distribution of $P$. cinnamomi in the tubs. The existence of three asymptomatic $C$. dentata does indicate that $P$. cinnamomi was not present uniformly within the tubs.

Analysis of variance of the nursery screening data indicated that the effect of treatment (family)

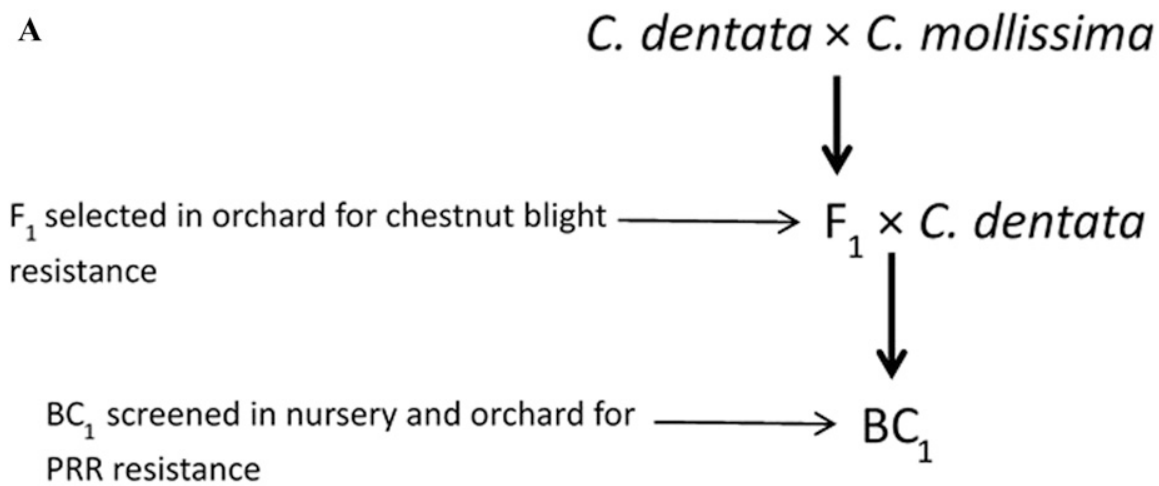

B

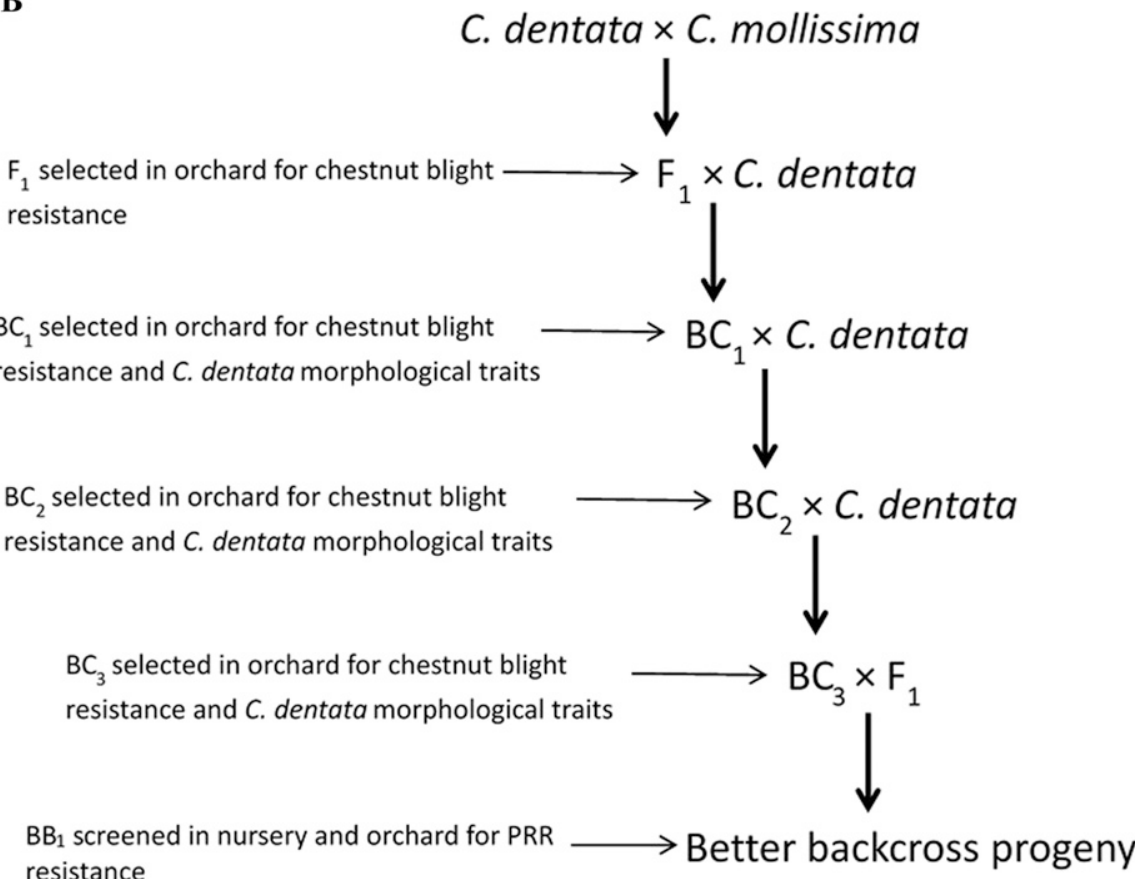

Fig. 1. (A) Crossing strategy used to generate first-backcross $\left(\mathrm{BC}_{1}\right)$ seedlings screened for resistance to phytophthora root rot (PRR). (B) Crossing strategy used to generate better-backcross $\left(\mathrm{BB}_{1}\right)$ seedlings screened for resistance to PRR.

Table 1. Hybrid Castanea families screened for phytophthora root rot resistance. Hybrid family names follow standard nomenclature used in the American Chestnut Foundation's dentataBase breeding records management system.

\begin{tabular}{|c|c|c|c|c|c|}
\hline Cross name & Pedigree & Cross type & Seed type & $\mathrm{n}$ & Resistance source \\
\hline TN-TTU-A4 × ALCLEB01 & $($ TNCLA1 $\times$ Gideon $) \times$ ALCLEB01 & $\mathrm{F}_{1} \times C$. dentata & $\mathrm{BC}_{1}$ & 27 & C. mollissima 'Gideon' \\
\hline TN-SM2-F1 $\times \mathrm{opB}_{3}$ & $($ TNMON8 $\times$ Nanking $) \times$ op $B_{3}$ & $\mathrm{~F}_{1} \times \mathrm{opB}_{3}$ & $\mathrm{BB}_{1}$ & 77 & C. mollissima 'Nanking' \\
\hline TN-TTU-A4 × ALCLEB04 & $($ TNCLA $1 \times$ Gideon $) \times$ ALCLEB0 4 & $\mathrm{~F}_{1} \times C$. dentata & $\mathrm{BC}_{1}$ & 23 & C. mollissima 'Gideon' \\
\hline TN-TTU-A4 × opF 1 & $($ TNCLA $1 \times$ Gideon $) \times \mathrm{opF}_{1}$ & $\mathrm{~F}_{1} \times \mathrm{opF}_{1}$ & $\mathrm{~F}_{2}$ & 116 & C. mollissima 'Gideon' \\
\hline TNSUM1 $\times$ TN-CN-6-193 & TNSUM1 × (TNLIN1 × Payne $)$ & C. dentata $\times \mathrm{F}_{1}$ & $\mathrm{BC}_{1}$ & 15 & C. mollissima 'Payne' \\
\hline TNMAC $1 \times$ TN-CN-4-195 & TNMAC1 × (TN-BF1-E10 × Amy $)$ & C. dentata $\times \mathrm{F}_{1}$ & $\mathrm{BC}_{1}$ & 40 & C. mollissima 'Amy' \\
\hline TNMAC1 $\times$ TN-CN-2-127 & TNMAC $1 \times($ TNRUT1 $\times$ Lindstrom 99 $)$ & C. dentata $\times \mathrm{F}_{1}$ & $\mathrm{BC}_{1}$ & 27 & C. mollissima 'Lindstrom 99' \\
\hline TN-TTU-A4 × ALCLEB05 & $($ TNCLA $1 \times$ Gideon $) \times$ ALCLEB05 & $\mathrm{F}_{1} \times C$. dentata & $\mathrm{BC}_{1}$ & 12 & C. mollissima 'Gideon' \\
\hline TN-CN-5-238 × ALCLEB01 & $(\mathrm{TN}-\mathrm{BF} 3-\mathrm{L} 10 \times$ Byron $) \times$ ALCLEB0 1 & $\mathrm{~F}_{1} \times C$. dentata & $\mathrm{BC}_{1}$ & 29 & C. mollissima 'Byron' \\
\hline TN-CN-3-262 × TNCAR1 & $($ TNLIN $1 \times$ op Chinese $) \times$ TNCAR 1 & $\mathrm{~F}_{1} \times C$. dentata & $\mathrm{BC}_{1}$ & 49 & C. mollissima 'Petersburg' \\
\hline C. mollissima & & & Control & 11 & \\
\hline C. dentata & & & Control & 13 & \\
\hline C. henryi & & & Control & 17 & \\
\hline
\end{tabular}

$\mathrm{BC}_{1}=$ first backcross; op = open pollinated; $\mathrm{BB}_{1}=$ better backcross; $\mathrm{F}_{2}=$ second filial generation. 


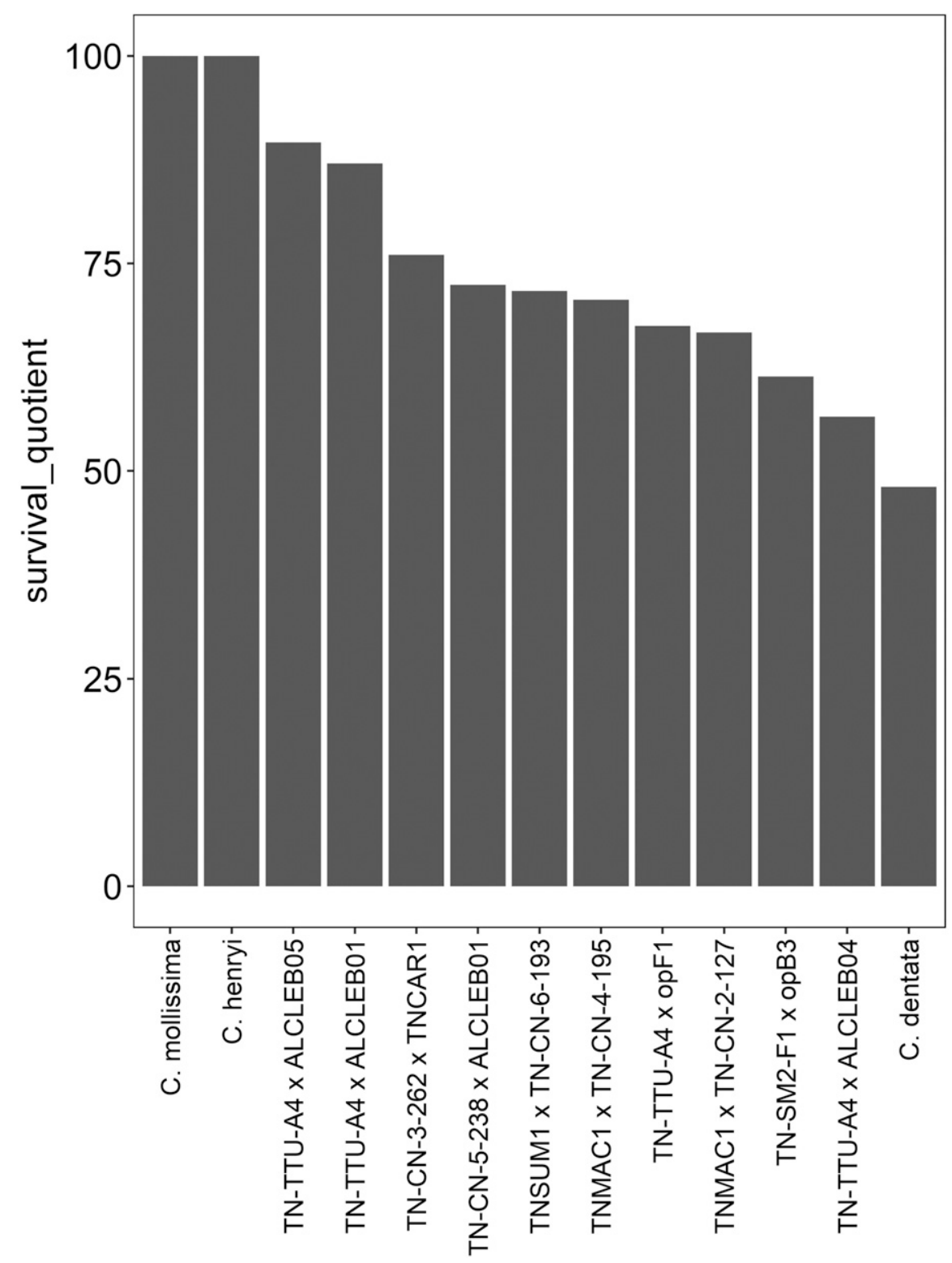

Fig. 2. Survival quotients (SQs) of hybrid Castanea families, $C$. henryi seedlings (resistant controls), $C$. mollissima seedlings (resistant controls), and $C$. dentata seedlings (susceptible controls) inoculated with Phytophthora cinnamomi. Families are arranged from high to low SQ value. $\mathrm{SQ}=\{[(1 \times \mathrm{n} 0)+$ $(0.5 \times \mathrm{n} 1)+(0.25 \times \mathrm{n} 2)] /$ Total number of seedlings $\} \times 100$, where $\mathrm{n} 0, \mathrm{n} 1$, and $\mathrm{n} 2$ are equal to the number of seedlings rated 0,1 , and 2 , respectively.

on symptom severity was highly significant $(P<$ $0.001)$. Analysis of variance also indicated a highly significant effect of block $(P<0.001)$. Multiple comparisons using Duncan's new multiple range test indicated that 8 of 10 hybrid families had mean symptom severity that was not significantly different from the susceptible $C$. dentata controls (Fig. 3). Although the average symptom severity of these families was high, all eight families contained multiple seedlings that were asymptomatic at the end of the nursery experiment. These individuals were retained for outplanting in the $P$. cinnamomi-positive orchard.

Two of 10 hybrid families (TN-TTU-A $4 \times$ ALCLEB05 and TN-TTU-A4 × ALCLEB01) had average symptom severity that was not significantly different from the PRR-resistant species C. mollissima and C. henryi (Fig. 3). Both of these $\mathrm{BC}_{1}$ families are descended from
C. mollissima, 'Gideon' (Table 1). Interestingly, a closely related family that shares the 'Gideon' source of PRR-resistance, TN-TTU-A4 $\times$ ALCLEB04, was not significantly different from the $C$. dentata susceptible control. There are a few possible explanations for these seemingly incongruous results. The first is that some variation in PRR resistance may exist among the pollen parents of these backcross families (i.e., the naturally occurring $C$. dentata trees ALCLEB01, ALCLEB04, and ALCLEB05). This seems highly unlikely, because previous studies did not find evidence of PRR resistance in C. dentata (Crandall et al., 1945; Jeffers et al., 2009). A more likely explanation can be attributed to the small number of trees in TN-TTU-A4 $\times$ ALCLEB01 and TN-TTU-A4 $\times$ ALCLEB05 (with 27 and 12 seedlings, respectively), and that some plants escaped infection, depressing the average symptom severity for these two families. The trial in a $P$. cinnamomi-infected orchard was designed to test plants that had missed pathogen exposure in the nursery trial, as well as provide results informative of field resistance.

In the assessment of orchard survival, 101 of 144 prescreened $\mathrm{BC}_{1}$ and $\mathrm{BB}_{1}$ plants were alive after 8 months of growth in the $P$. cinnamomipositive orchard in Aug. 2016. These 101 plants represent $70 \%$ of the 144 seedlings identified as least symptomatic in the 2015 nursery trials that were transplanted to the $P$. cinnamomi-positive orchard in Jan. 2016. In previous plantings at the Allatoona orchard, hybrid seedlings that had not been prescreened for PRR resistance experienced very low survival compared with PRRresistant $C$. mollissima controls. As of Aug. 2016, for example, only 6 of $46(13 \%) C$. dentata seedlings, 5 of 40 (13\%) nonscreened $\mathrm{BC}_{3} \mathrm{~F}_{2}$ seedlings, 71 of $338(21 \%)$ nonscreened $\mathrm{BC}_{3} \mathrm{~F}_{3}$ seedlings, 10 of 71 (14\%) nonscreened $\mathrm{BC}_{1}$ seedlings, and 36 of $47(77 \%)$ Castanea mollissima seedlings were alive after at least 1 year of growth in the $P$. cinnamomi-positive orchard. Because hybrid families that had not been prescreened for PRR resistance were planted in earlier years than our prescreened hybrid seedlings, a statistical analysis of these data would not have been appropriate. However, the fact that $70 \%$ of our nursery-screened hybrids were alive after nearly an entire growing season in a $P$. cinnamomi-positive orchard does suggest that our nursery trials were effective in reducing the number of susceptible seedlings planted in the field.

One of the major goals of the american chestnut restoration effort is to produce a population of advanced backcross trees with the chestnut blight resistance of C. mollissima, but with all other phenotypic traits of $C$. dentata. Researchers have pursued this goal in earnest since the early 1980s (Burnham, 1988); however, the need for host resistance to PRR in these populations only became apparent in 2003 (Jeffers et al., 2009). A population of trees with resistance to both chestnut blight and PRR would facilitate successful plantings of $C$. dentata-type hybrids in the southern portion of the american chestnut's distribution, where PRR-induced planting failures have been most common (Jeffers et al., 2009).

As a first step toward producing populations of PRR-resistant plants for the American Chestnut Foundation's breeding program in the southeastern United States, we have generated PRR-resistant seedlings in hybrid families derived from multiple sources of resistance. Although hybrid derivatives of $C$. mollissima 'Nanking' have been assessed previously for PRR resistance (Zhebentyayeva et al., 2014), our study represents the first attempt to identify PRR resistance in descendants of the following C. mollissima cultivars: Amy, Byron, Gideon, Lindstrom 99, Payne, and Petersburg. Of the progeny challenged with $P$. cinnamomi in our study, seedlings derived from the $C$. mollissima cultivars Amy, Byron, Gideon, Nanking, and Petersburg are still alive and growing in a $P$. cinnamomi-positive orchard as of Nov. 2018. In addition to the host resistance to PRR identified here, the cultivar grandparents of 

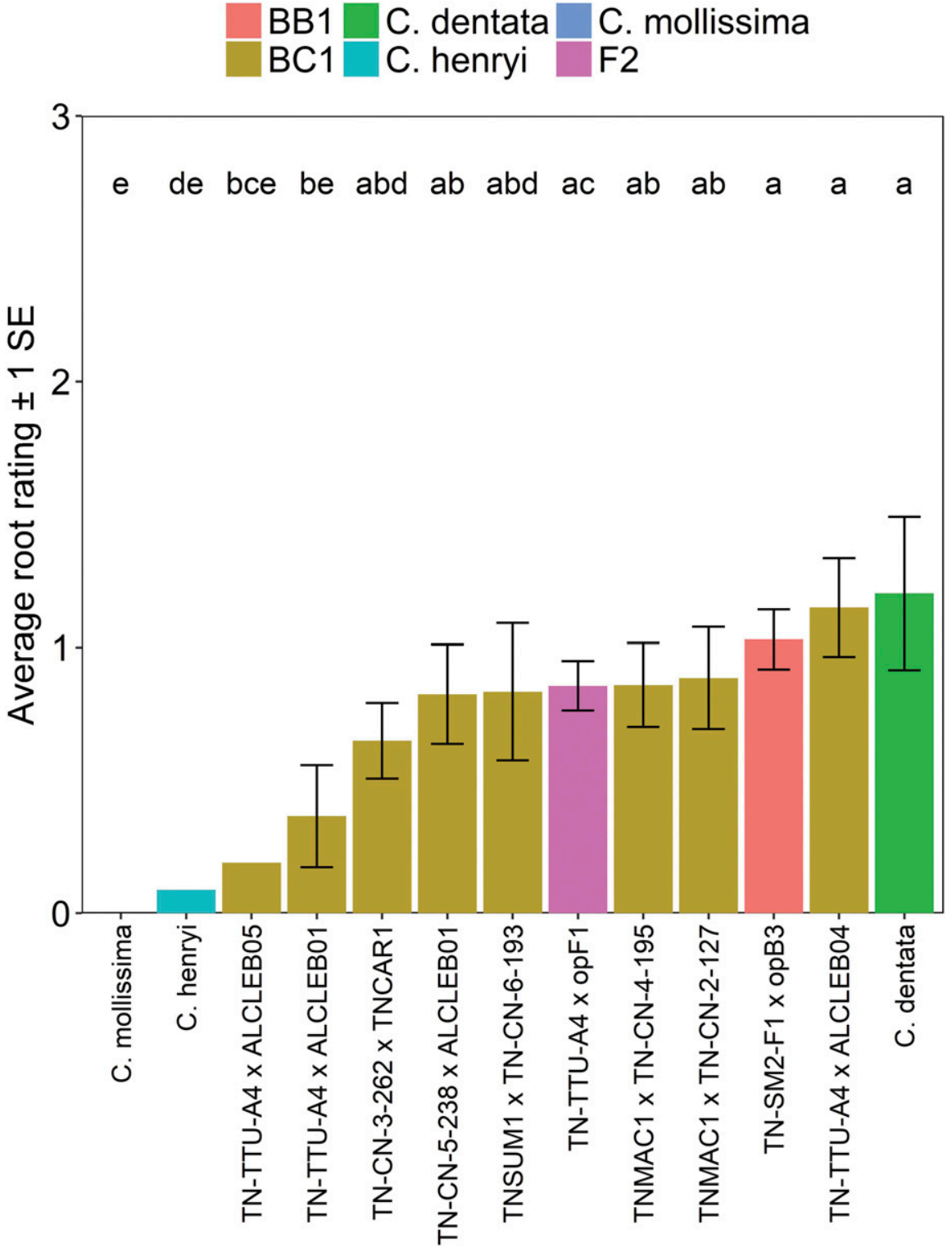

Fig. 3. Mean symptom severity of phytophthora root rot (PRR) in hybrid Castanea families, $C$. henryi seedlings (resistant controls), $C$. mollissima seedlings (resistant controls), and $C$. dentata seedlings (susceptible controls). Error bars represent 1 SEM. Columns with the same letter are not significantly different according to Duncan's new multiple range test $(\alpha=0.05)$. Column colors represent seed type of the different groups screened for disease resistance.

the hybrid progeny also have several desirable agronomic and culinary traits, including high average nut mass, high yield, and superior taste (Metaxas, 2013). Consequently, the hybrid progeny screened here may also be of interest to plant breeders with a focus on chestnut as a nut crop for the southern United States.

\section{Literature Cited}

Alexander, M.T., L.M. Worthen, and J.H. Craddock. 2005. Conservation of Castanea dentata germplasm of the southeastern United States. Acta Hort. 693:485-490.

Anagnostakis, S.L. 2001. The effect of multiple importations of pests and pathogens on a native tree. Biol. Invasions 3:245-254.

Arnhold, E. 2013. Package in the R environment for analysis of variance and complementary analyses. Braz. J. Vet. Res. Anim. Sci. 50:488-492.

Burnham, C.R. 1988. The restoration of the American Chestnut. Amer. Sci. 76:478-487.
Clark, S.L., S.E. Schlarbaum, and F.V. Hebard. 2014. The first research plantings of thirdgeneration, third-backcross American chestnut (Castanea dentata) in the southeastern United States. Acta Hort. 1019:39-44.

Crandall, B.S., G.F. Gravatt, and M.M. Ryan. 1945 Root disease of Castanea species and some coniferous and broadleaf nursery stocks, caused by Phytophthora cinnamomi. Phytopathology 35:162-180.

Ferguson, A.J. and S.N. Jeffers. 1999. Detecting multiple species of Phytophthora in container mixes from ornamental crop nurseries. Plant Dis. 83(12):1129-1136.

Fitzsimmons, S.F. 2016. Phytophthora cinnamomi nut Tree Nwsl. 21(1):6.

Hebard, F. 2005. The backcross breeding program of the American Chestnut Foundation. J. Amer. Chestnut Foundation 19(2):55-78.

James, J.B. 2011a. Phytophthora: The stealthy killer. J. Amer. Chestnut Foundation 25(4):9-11. isolated from chestnuts in Pennsylvania. Chest-
James, J.B. 2011b. Phytophthora: The stealthy killer, part 2. J. Amer. Chestnut Foundation 25(5):14-17. Jeffers, S.N. 2015. Protocol 07-11.1: V8 agar (V8A) or broth. In: K. Ivors (ed.). Laboratory protocols for Phytophthora species. 1 Mar. 2015. <https://www.apsnet.org/apsstore/Pages/ protocolsTOCdes.aspx $>$.

Jeffers, S.N., J.B. James, and P.H. Sisco. 2009 Screening for resistance to Phytophthora cinnamomi in hybrid seedlings of American chestnut. Proc. Fourth Meeting of the International Union of Forest Research Organization (IUFRO) Working Party S07.02.09: Phytophthoras in Forests and Natural Ecosystems. E.M. Goheen and S.J. Frankel (tech. coords.). Gen. Tech. Rep. PSW-GTR-221. USDA, Forest Service, Pacific Southwest Research Station, Albany, CA. p. $188-194$.

Jeffers, S.N., I.M. Meadows, J.B. James, and P.H. Sisco. 2012. Resistance to Phytophthora cinnamomi among seedlings from backcross families of hybrid American chestnut. Proc. Fourth International Workshop on the Genetics of Host-Parasite Interactions in Forestry: Disease and Insect Resistance in Forest Trees. R.A Sniezko, A.D. Yanchuk, J.T. Kliejunas, K.M. Palmieri, J.M. Alexander and S.J. Frankel (tech. coords.). Gen. Tech. Rep. PSW-GTR240. USDA, Forest Service, Pacific Southwest Research Station, Albany, CA. p. 194-195.

Metaxas, A.M. 2013. Chestnut (Castanea spp.) cultivar evaluation for commercial chestnut production in Hamilton County, Tennessee. Univ. of Tennessee, Chattanooga, TN, MS thesis.

Paillet, F.L. 1993. Growth form and life histories of American chestnut and Allegheny and Ozark chinquapin at various North American sites. Bull. Torrey Bot. Club 120(3):257-268.

Paillet, F.L. 2002. Chestnut: History and ecology of a transformed species. J. Biogeogr. 29:1517-1530.

$\mathrm{R}$ Core Team. 2018. $\mathrm{R}$ version 3.5.0: A language and environment for statistical computing. $\mathrm{R}$ version 3.5.0 Foundation for Statistical Computing, Vienna, Austria. 29 April 2018. $<$ https:// www.R-project.org/>.

Santos, C., C.D. Nelson, T. Zhebentyayeva, H. Machado, J. Gomes-Laranjo, and R.L. Costa. 2017. First interspecific genetic linkage map for Castanea sativa $\times$ Castanea crenata revealed QTLs for resistance to Phytophthora cinnamomi. PLoS One 12(9):E0184381.

Sena, K., E. Crocker, P. Vincelli, and C. Barton. 2018. Phytophthora cinnamomi as a driver of forest change: Implications for conservation and management. For. Ecol. Mgt. 409:799-807.

Sisco, P.H. 2009. Outlook for blight-resistant American chestnut trees. National Proceedings: Forest and Conservation Nursery Associations-2008. R.K. Dumroese and L.E. Riley (tech. coords.) Proc. RMRS-P-58. USDA, Forest Service, Rocky Mountain Research Station, Fort Collins, CO. p. 61-68.

Steiner, K.C., J.W. Westbrook, F.V. Hebard, L.L. Georgi, W.A. Powell, and S.F. Fitzsimmons. 2017. Rescue of American chestnut with extraspecific genes following its destruction by a naturalized pathogen. New For. 48(2):317-336.

Westbrook, J. 2017. Genomic selection for disease resistance in American chestnut backcross populations. Chestnut: J. Amer. Chestnut Foundation. 31(3):38-42.

Zhebentyayeva, T., M. Staton, B. Olukolu, A. Chandra, S. Jeffers, J. James, P. Sisco, F. Hebard, L. Georgi, C.D. Nelson, and A.G. Abbott. 2014. Genetic and genomic resources for mapping resistance to root rot disease (Phytophthora cinnamomi) in chestnut. Acta Hort. 1019:263-270. 